\title{
Challenges of higher education related to e-learning in developing countries during COVID-19 spread: a review of the perspectives of students, instructors, policymakers, and ICT experts
}

\author{
Soraya Zarei ${ }^{1} \cdot$ Shahriar Mohammadi ${ }^{1}$ \\ Received: 21 April 2021 / Accepted: 26 May 2021 / Published online: 7 June 2021 \\ (C) The Author(s), under exclusive licence to Springer-Verlag GmbH Germany, part of Springer Nature 2021
}

\begin{abstract}
The COVID-19 pandemic brought about many critical issues in all aspects such as economy, environment, health, and lifestyle, but people always try to find some response to crisis in different conditions. E-learning is defined as an elaborate response aiming at continuing education during the COVID-19 pandemic. It seems that developed countries have established and adjusted their technological infrastructures for the transition from a face-to-face education to a digital one. In contrast, developing countries were not completely prepared for this transition. Improper and deficient technological and practical fundamentals have been causing problems for all students, instructors, and other involved individuals. Therefore, we reviewed the challenges that have arisen from e-learning during the COVID-19 outbreak in different parts of tertiary education focusing on underprivileged countries.
\end{abstract}

Keywords Learning · COVID-19 · Developing countries

\section{Introduction}

The newly emerged COVID-19 pandemic brought about a global crisis affecting all aspects of human life. During about 10 months, more than 200 countries throughout the world had to socially, economically, environmentally, and clinically cope with the pandemic (Aloysius et al. 2020) (Gholipour et al. 2021; Gholipour et al. 2020). These effects can be directly related to the pandemic, such as increased generation of medical waste (Kalantary et al. 2021), or indirectly related to the consequences of the pandemic in changing the lifestyle of citizens such as reducing waste recycling (Yousefi et al. 2021). To reduce the transmission of the disease, many businesses have been suspended or shut down. Service delivery systems have received more funds, and institutes offering traditional or face-to-face education have been closed and forced to migrate to e-learning and distance education (Mishra et al. 2020; Donthu and Gustafsson 2020; Favale et al. 2020). The COVID-19 pandemic has led to using specific guidelines for

Responsible Editor: Lotfi Aleya

Shahriar Mohammadi mohammadi@kntu.ac.ir

1 Information Technology Group, Department of Industrial Engineering, K.N. Toosi University of Technology, Tehran, Iran many activities in the community such as education, business, and municipal services (Torkashvand et al. 2021). E-learning is defined as a flexible, interactive, self-pacing, and elaborate pedagogical method introducing educational approaches using a wide variety of platforms. After the spread of COVID-19, universities and educational institutes had two options for the migration to e-learning; the first option was buying or using other platforms, and universities had to integrate the present distance-learning platforms. The other option was for the universities to create or use their own platforms (Adedoyin and Soykan 2020). Regardless of the selected way of transitioning from traditional education to a distance one, e-learning can bring about some benefits, especially for the future plans for developing distance learning. To exemplify, by running a wellrounded digital platform, universities become prepared for possible health emergencies and crises. In addition, they can end up with a huge number of innovations making significant positive effects on education (Brem et al. 2020). Interestingly, during the closure of universities and educational institutes, the internet traffic used by e-learning platforms was employed as an up-to-the-minute way to identify the marginalized or needy students and individuals for further financial and social support (Adedoyin and Soykan 2020).

Despite the abovementioned benefits of the development of e-learning, it seems that this method is compatible with tertiary education in developed countries where sufficient 
and effective digital infrastructures have been developed in advance and high-speed and continual internet is available for both instructors and students. Moreover, a great fraction of students can use updated laptops or computers to participate in digital classes. In sharp contrast, in underdeveloped countries, developing e-learning for universities was a challenging process for all the involved individuals including students, instructors, policymakers, and the information and communication technology (ICT) experts. (Adnan and Anwar 2020).

Since reviewing all aspects of expanding e-learning in universities during the pandemic is important, some researchers have focused on the challenges and opportunities of the COVID-19 spread, but few works have been conducted on the differences between the developing and developed parts of the world. This article discusses the challenges created by the forced development of e-learning during the COVID-19 outbreak for all the involved individuals including students, instructors, managers, and ICT experts in higher education in underdeveloped countries.

\section{Method}

This study was conducted by reviewing published articles related to education in the COVID-19 era and its consequence on e-learning. For this purpose, three consecutive steps were performed as follows.

Literature search Articles were searched using keywords including "COVID-19", "Coronavirus disease", "education", and "e-learning" in Scopus, Web of Knowledge, and PubMed. According to the search protocol, keywords must appear in the title, or abstract, or keyword. The search limit also included articles published in 2020 and 2021.

Eligibility criteria The final papers were chosen on the basis of the eligibility criteria; hence, all studies that included (1) effects of the COVID-19 pandemic on education, (2) challenges faced by students, (3) instructors' challenges, and (4) educational policymakers and strategic managers were selected.

Study selection The literature was screened independently by the authors, based on the criteria mentioned above. After the screening stage, 27 articles were selected which contain any information on the purpose of this study.

\section{Challenges faced by higher education students}

It is estimated that the COVID-19 outbreak has confined a large number of students to their homes. In these conditions, students have to attend their classes in different platforms and using digital education. One of the main requirements of distance learning is a safe and fast internet connection. Access to the technical requirements of online education is not a significant problem in developed countries because laptops and smartphones with a high-speed internet connection are available for almost all the students and teachers in different parts of these countries (Ahmadi and Ilmiani 2020); however, as shown in Fig. 1, online courses might be completely or partially inaccessible to the students in developing countries due to a poor internet connection and also in many cases students may stay logged out (Sangster et al. 2020; Diab and Elgahsh 2020). In developing countries, a number of students especially those who are living in rural and underprivileged areas do not have access to sufficient and efficient internet connection, which leads to several problems in their education. For example, during city lockdown, about $70 \%$ of Indian students attended online classes, the majority of which used android smartphones, but digital platforms used for e-learning are not compatible with smartphones. This also deteriorates the students' performance (Adedoyin and Soykan 2020). They also mentioned that houses were not a desirable location for studying. More than $30 \%$ of the students complained about poor internet connection. All those problems led to self-mentioned depression, stress, and anxiety in $42 \%$ of the students (Kapasia et al. 2020). Based on the students' perspective in India, $77 \%$ of the studied students noted that their main problems in participating in online examinations were internet connectivity (Bisht et al. 2020). In addition to connection-related problems, not all the students could afford to purchase a laptop or a personal computer. It has been reported that a great number of students come from poor or low-income families (Fry and Cilluffo 2019), and preparing technological requirements for remote education is really hard for these students and their families, which leads to educational inequalities (Hasan et al. 2020; Wong et al. 2015). The lack of access to updated technologies can also cause psychological distress. It has been proven that the risk of mental stress arising from inequalities in poor students is approximately high (Jiang and Review 2020). For example, $63 \%$ of nursing students in Nepal felt anxiety because of the problems that occurred during online classes (Subedi et al. 2020).

Studying and conducting research at home are other challenging issues for students, especially for those who work. The home environment is not a suitable location for education because students may get distracted by other family members or pets. For example, at the time of interviews, tests, homework, or other educational activities, students might get distracted and not be able to meet their assignments' deadlines (Sangster et al. 2020). In addition, using outdated tools might hamper the availability of educational content offered in distance learning. It is also reported that students were faced with different problems when taking e-quizzes because of using outdated software and hardware (Bisht et al. 2020). Out-of- 
Fig. 1 Challenges faced by students in developing countries during the COVID-19 pandemic

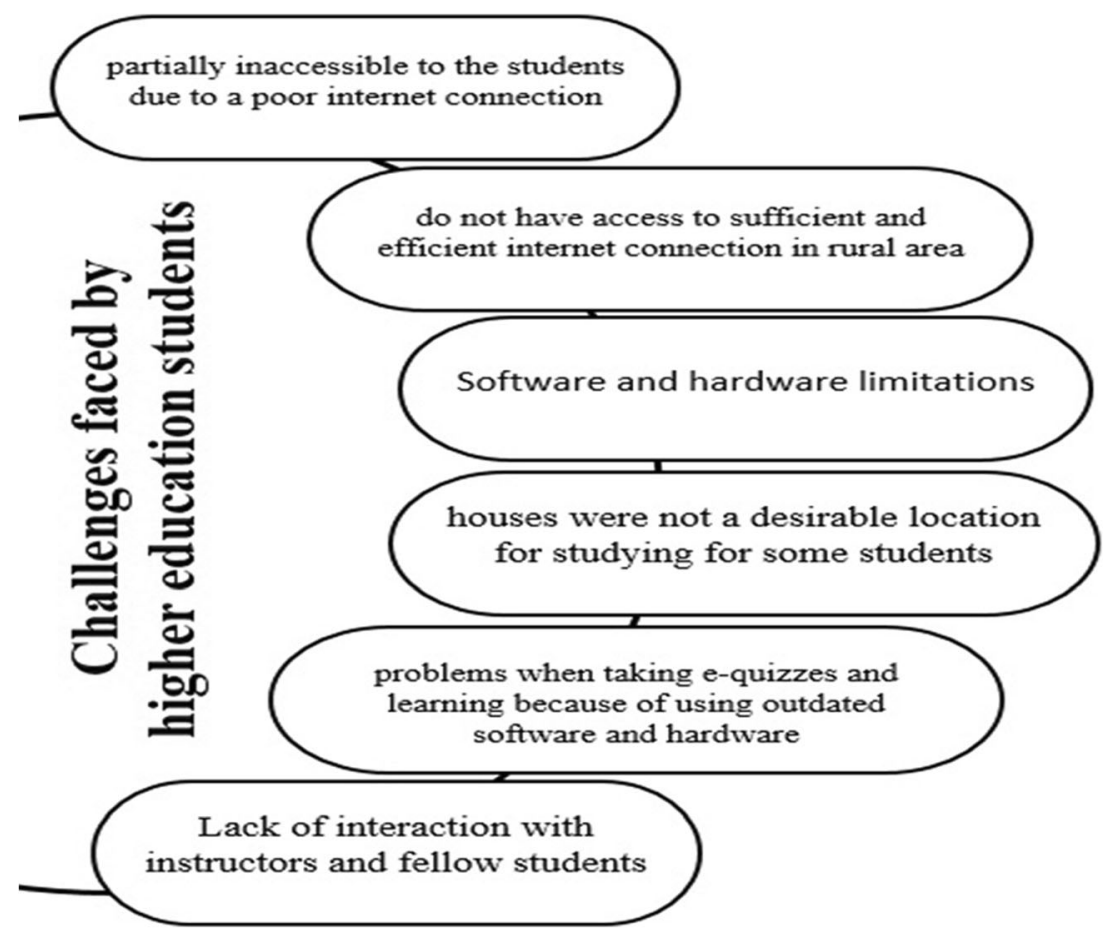

date digital tools might not be compatible with suitable browsers for e-learning, and the possibility of losing scores for marginalized students is higher than others. For instance, in the study on the students of STKIP Pamane Talino Philippines, $78 \%$ of the participants mentioned that incompatibility of their gadgets with educational platforms caused some problems because they had to use their smartphone to attend online classes, which required installing and reinstalling several applications and unreasonably filling up their phone memories (Agung and Surtikanti 2020). Based on the students' perception, Whatsapp was the most internet-friendly application for online classes (Agung and Surtikanti 2020).

In normal conditions, learners used the free internet connection provided by educational institutes, but after the COVID-19 spread, they have to buy internet traffic, and it is not affordable for some learners in underdeveloped nations. In a study conducted in Pakistan, expensive internet connection was considered a problem of online education by $11 \%$ of undergraduates and postgraduates (Adnan and Anwar 2020). Moreover, to use digital libraries, internet connection and membership fee are needed; however, several universities do not have digital libraries to offer their students. In addition, the quality and quantity of e-content and e-resources for students is not enough, especially in developing countries, because these countries were not ready for these conditions in advance, and they do not have suitable or complete digital infrastructures (Adnan and Anwar 2020). Lack of interaction with instructors and fellow students is another major problem. Based on the results of a study conducted in Iran, medical students stated lack of teacher interaction as a significant challenge during the COVID-19 spread (Afshari et al. 2020). Some students are classified as tactile learners who need to have discussions with their teachers in a face-to-face manner to understand the complicated digitally taught content. All these problems might lead to stress and consequently, mental health issues in marginalized students, and these inequalities are inconsistent with educational justice (Britt 2006).

Digital competence which is defined as skills, attitudes, and knowledge required to attend digital classes is another important challenge of distance learning (Ferrari 2013). In traditional learning, students are observed and monitored by supervisors, instructors as well as research fellows, but in long-term e-learning classes, students might be disappointed and refuse to attend classes; thus, they need to be highly motivated to continue this type of education for a long time (Diab and Elgahsh 2020).

The development of distance learning can also lead to some general problems for students regardless of their living location. It might increase the rate of insufficient physical activity in students. Furthermore, an increase in web surfing, disruption of sleep patterns, and reduction in social and interpersonal relationships could happen for all students during the closure of universities and distance learning (Wang et al. 2020).

\section{Instructors' challenges}

Instructors have a wide range of responsibilities including research, teaching, assessing students as well as guidance 
and supervision of graduate and undergraduate students. The issues related to e-learning for instructors are not specific to developing countries; nevertheless, owing to the fact that this educational method has recently been launched in these countries, they might face newer problems which they have not encountered before (Chang and Fang 2020) (see Table 1). Setting up a new pedagogical method creates a significant additional workload for instructors. For example, it is time-consuming work to properly hold user-friendly classes and upload them to a digital platform. Things get worse when trainers do not have enough technical knowledge to utilize virtual platforms (Bhuasiri et al. 2012; Abdel-Gawad et al. 2015; Alqahtani and Rajkhan 2020). Based on the internet-based responses of instructors, $30 \%$ of teachers have felt psychological stress due to an increased workload during the COVID-19 outbreak. Moreover, $70 \%$ of them have experienced increased workload (Chang and Fang 2020). Many of the instructors in developing countries are inexperienced in turning their knowledge into virtual content. The e-learning method requires several hours of thinking to find out how a concept can be taught in the form of virtual education. Additionally, it is a tough job to keep students motivated, and teachers have to think critically to encourage learners to meet their assignments' deadlines (Alqahtani and Rajkhan 2020).

Another major challenge faced by teachers is the assessment problem. While there are a variety of assessment methods including multi-choice questioning, constructed response, sentence completion, performance-based formats, short answers, matching, and other similar methods, there is no definitive guarantee to prevent cheating in any of the assessment methods used in e-learning. In addition, after selecting the correct way, the instructors should convert their assessment method to an online standard one which is rather difficult. Nguyen et al. (2020) suggested using some assessment strategies such as higher-order thinking multiple choice questions, novel higher-order thinking short answer questions, and increasing assessment frequency to minimize online cheating (Nguyen et al. 2020).
During the COVID-19 pandemic, due to the closure of educational institutes, progressive interaction between instructors and learners has stopped which has led to an incomplete process of transferring and sharing knowledge. This could be exasperating for both instructors and students (Lambert and Pedagogy 2020). Ultimately, because of a lack of face-to-face learner-teacher interaction, the social skills of students cannot be promoted (Wadhwa and Khatak 2020). While, in some fields, distance learning is reluctantly accepted as an inevitable aspect of the health emergency due to the risk of virus transmission, the possibility of this type of education for some fields such as sports, medicine, and nursing is very low. In these cases, blended learning is recommended to reduce the presence of students in universities and promote the hands-on skills and experiences of students (Lambert and Pedagogy 2020; Hoq 2020). Medical students in Jordan asserted that elearning is not fulfilling for them; therefore, blended learning might be a more suitable method for medical education (AlBalas et al. 2020).

\section{Educational policymakers and strategic managers}

It is clear that creating a new education system is a timeand money-consuming process. Managers of educational institutes should be alert about ethical, structural, social, and behavioral limitations of the new learning method (Fig. 2). Unfortunately, there are few suitable technical and fundamental infrastructures in universities in developing countries, and only some well-known or national ones have experience in operating virtual education prior to the COVID-19 outbreak. For example, in Iraq and Syria, they lost their technological infrastructure because of war, and facing the COVID-19 pandemic has worsened the situation (Hussein et al. 2020). In these areas, national radio and television programs can be used to broadcast primary or secondary school classes instead of holding online classes (Gyimah 2020); however, it seems that this method does not work for tertiary education.

Table 1 Instructors' challenges during the COVID-19 pandemic

\begin{tabular}{|c|c|c|}
\hline Issue & Challenges & Reference \\
\hline Job & $\begin{array}{l}\checkmark \text { Significant additional workload for instructors } \\
\checkmark \text { Psychological stress due to an increased workload }\end{array}$ & Bhuasiri et al. (2012), Chang and Fang (2020) \\
\hline Equipment & $\begin{array}{l}\checkmark \text { Technical knowledge to utilize virtual platforms } \\
\checkmark \text { Possibility of e-learning for some fields such as sports, medicine, and } \\
\text { nursing is very low }\end{array}$ & $\begin{array}{l}\text { Abdel-Gawad et al. (2015); Alqahtani and Rajkhan (2020), Hoq } \\
2020\end{array}$ \\
\hline Students & $\begin{array}{l}\checkmark \text { Keep students motivated } \\
\checkmark \text { Prevent cheating } \\
\checkmark \text { Interaction between instructors and learners has stopped }\end{array}$ & $\begin{array}{l}\text { Alqahtani and Rajkhan (2020), Nguyen et al. (2020), Lambert } \\
\text { and Pedagogy (2020) }\end{array}$ \\
\hline
\end{tabular}




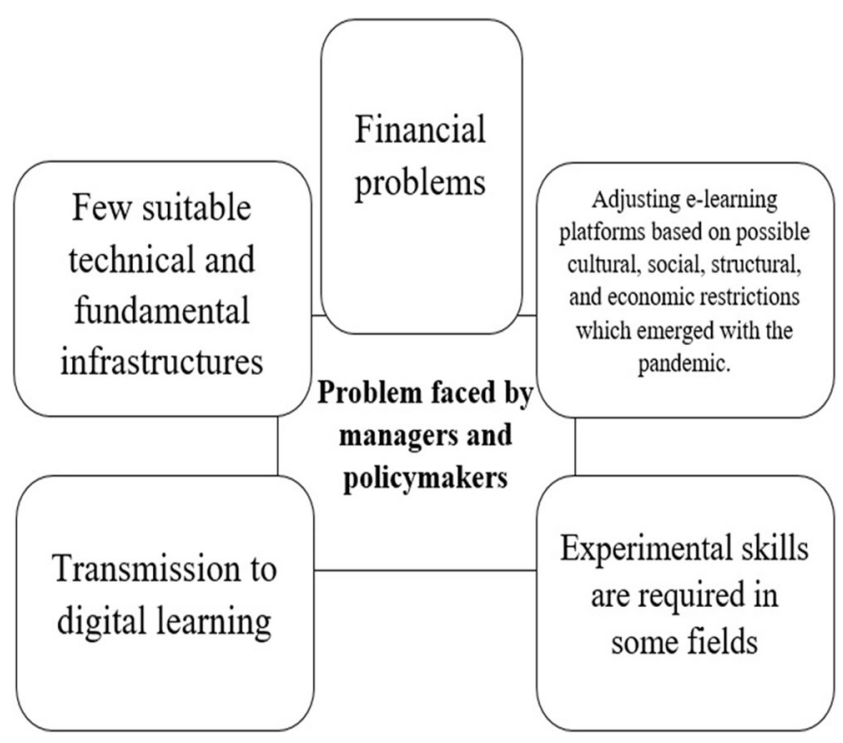

Fig. 2 Problem faced by managers and policymakers during the COVID19 pandemic

The majority of universities established their e-learning platforms just after the pandemic, and the platforms have not been adjusted based on possible cultural, social, structural, and economic restrictions which emerged with the COVID19 outbreak, social distancing, and quarantine rules (Settersten $\mathrm{Jr}$ et al. 2020). This has been very problematic for policymakers, and they are continuously receiving complaints from students, instructors, ICT experts, and other involved groups.

The main problem faced by managers and policymakers is the organization of a well-rounded educational plan to reach the main goals of training. Universities and institutes were previously managed on the basis of traditional education, and now they have to experience a transmission to digital learning (Adedoyin and Soykan 2020). In the newer platforms, the methods by which students receive scientific information and use them have been significantly changed.

Another obvious issue regarding the development of distance learning is financial problems. In Saudi Arabia, it is reported that universities had to hire new ICT experts to provide support for teachers and students. In addition, they had to purchase new platforms that required expensive infrastructures (Hoq 2020). Universities and institutes are usually financially supported by the local or national government, but no additional money is allocated to these educational institutes to purchase digital platforms and other required environments including content production rooms and digital laboratories. Adnan and Anwar (2020) reported that although the development of distance learning is a critical response to the COVID-19 crisis by universities, the financial resources of the universities in Pakistan are not enough, and universities do not receive any additional fund for these expenses (Adnan and Anwar 2020).
In some cases, the content of the curriculum is not suitable to be taught digitally. In these cases, managers should make a decision to replace or rewrite a syllabus or to transfer it to future semesters; in other terms, there are several uncertainties about suitable or unsuitable syllabi for distance learning (Shea and Sciences 2020). In some fields in which experimental skills are required, several innovations are needed to make education more sensible (Leszczyński et al. 2018). While virtual laboratories and massive open online courses (MOOCs) can work as alternative remedies (Iqbal et al. 2015), they are not perfect for all courses, and equipping and setting up such laboratories is very expensive; therefore, holding face-to-face classes in a very limited way is inevitable (Adedoyin and Soykan 2020). Some countries such as those of the Middle East are suffering from the US sanction regime (Baloch et al. 2020); therefore, in these countries, some e-learning applications that are designed by US companies do not work properly. Moreover, creating an account for some applications or platforms used in digital education is impossible for the students in these areas, and it can cause some problems for instructors and learners as well as policymakers.

\section{ICT experts}

ICT is the heart of digital education in universities. The ICT experts must technically and practically support both instructors and students and also present reports to the heads of faculties and universities. With the emerging of COVID-19, the workload of the ICT and IT experts has especially rocketed. In Nigeria, a limited adaptation of ICT has been reported, and ICT experts are not well-trained to facilitate virtual learning (Lawal et al. 2020). Newly adjusted platforms in many cases require updating or repairing, which increases the workload and burden of ICT experts. Almost all universities that did not have e-learning platforms had to provide or purchase one. ICT experts are the means of communication between universities and the providers of these platforms, and they have to make a number of calls to find a better and compatible platform for universities. After buying the platform, updating and upgrading it and finding its shortcomings are the responsibility of the ICT experts (Adedoyin and Soykan 2020). At the same time, they have to arrange different workshops for instructors aiming at teaching them to produce educational materials or upload the materials, etc. In addition, almost every day, they are being called for technical support by instructors or students (Adedoyin and Soykan 2020).

\section{Opportunities}

While the COVID-19 outbreak brought about several educational difficulties, especially in developing countries, it made 
some opportunities as well. Firstly, universities and educational institutes gained insight about their shortcomings and are more prepared to cope with a similar and possible pandemic situation. For example, China was able to deal with the transition from traditional education to a digital one because it had a valuable experience of fighting with SARS and MERS. In addition, the COVID-19 pandemic forced universities to improve their technological infrastructures for distance learning so they can continue their courses during other health emergencies. Moreover, learners and teachers tried to improve their digital knowledge to participate in online classes. Most importantly, these limitations and difficulties have led to a great number of innovations for the promotion and development of e-learning methods. For example, several approaches have been introduced to minimize cheating in digital examinations. In some areas, technological innovations driven from improved digital collaborations helped to bring about some scientific achievements for the eradication of the pandemic.

\section{Conclusion}

The COVID-19 spread has been making difficulties in all aspects of human life. Like many sectors of communities, universities have been affected by the pandemic. Their problems are more apparent in developing countries owing to the lack of technological and financial infrastructures. It seems that all the involved individuals including students, instructors, policymakers as well as ICT experts are tackling some problems related to the lack of preparation in advance. Despite the difficulties caused by COVID-19 in educational systems, there have been some benefits as well. Defective infrastructures have been improved in a short time. Moreover, all the involved individuals have been compelled to increase their technical knowledge of distance learning.

\section{Acknowledgements Not applicable}

Authors' contributions SZ, SM: investigation, writing —original draft, writing - review and editing.

Funding Not applicable

Data availability All data generated or analyzed during this study are included in this published article.

\section{Declarations}

Ethics approval Not applicable

Consent to participate Not applicable

Consent for publication Not applicable
Competing interests The authors declare that they have no competing interests.

\section{References}

Abdel-Gawad T, Woollard JJIJT, Learning D (2015) Critical success factors for implementing classless e-learning systems in the Egyptian higher education. Int J Instr Technol Distance Learn 12: $29-40$

Adedoyin OB, Soykan EJILE (2020) Covid-19 pandemic and online learning: the challenges and opportunities. Interact Learn Environ: 1-13. https://doi.org/10.1080/10494820.2020.1813180

Adnan M, Anwar KJOS (2020) Online learning amid the COVID-19 pandemic: students' perspectives. J Pedagogical Sociol Psychol 2(1):45-51

Afshari P, Abedi P, Eslami K, et al (2020) The views of medical students about e-learning during pandemic of COVID-19 in Iran. https://doi. org/10.21203/rs.3.rs-47582/v1

Agung ASN, Surtikanti MW and Quinones CAJSJSdH. (2020) Students' perception of online learning during COVID-19 pandemic: a case study on the English students of STKIP Pamane Talino. SOSHUM: Jurnal Sosial Dan Humaniora 10: 225-235.

Ahmadi A, Ilmiani AMJDI (2020) The use of teaching media in Arabic language teaching during Covid-19 pandemic. Dinamika Ilmu 20: 307-322

Al-Balas M, Al-Balas HI, Jaber HM et al (2020) Distance learning in clinical medical education amid COVID-19 pandemic in Jordan: current situation, challenges, and perspectives. BMC Medical Education 20:341

Aloysius MM, Thatti A, Gupta A, et al (2020) COVID-19 presenting as acute pancreatitis

Alqahtani AY, Rajkhan AAJES (2020) E-learning critical success factors during the COVID-19 pandemic: a comprehensive analysis of Elearning managerial perspectives. Educ Sci 10(9):216

Baloch Z, Ma Z, Ji Y, Ghanbari M, Pan Q, Aljabr W (2020) Unique challenges to control the spread of COVID-19 in the Middle East. J Infect Public Health 13:1247-1250

Bhuasiri W, Xaymoungkhoun O, Zo H, Rho JJ, Ciganek AP (2012) Critical success factors for e-learning in developing countries: a comparative analysis between ICT experts and faculty. Comput Educ 58:843-855

Bisht RK, Jasola S, Bisht IPJAE et al (2020) Acceptability and challenges of online higher education in the era of COVID-19: a study of students' perspective. Asian Educ Dev Stud doi ahead-of-print. https://doi.org/10.1108/AEDS-05-2020-0119

Brem A, Viardot E, Nylund PAJTF et al (2020) Implications of the coronavirus (COVID-19) outbreak for innovation: which technologies will improve our lives? Technol Forecast Soc Chang 163: 120451

Britt RJRT (2006) Online education: a survey of faculty and students. Radiol Technol 77:183-190

Chang C-L, Fang M (2020) E-learning and online instructions of higher education during the 2019 novel coronavirus diseases (COVID-19) epidemic. Journal of Physics: Conference Series. IOP Publishing, 012166

Diab GMAE-H, Elgahsh NFJAJN (2020) E-learning during COVID-19 pandemic: obstacles faced nursing students and its effect on their attitudes while applying it. Am J Nurs 9:300-314

Donthu N, Gustafsson AJJ (2020) Effects of COVID-19 on business and research. J Bus Res 117:284

Favale T, Soro F, Trevisan M, Drago I, Mellia M (2020) Campus traffic and e-Learning during COVID-19 pandemic. Comput Netw 176: 107290 
Ferrari A (2013) DIGCOMP: a framework for developing and understanding digital competence in Europe: Publications Office of the European Union Luxembourg. https://doi.org/10.2788/52966

Fry R, Cilluffo A (2019) A rising share of undergraduates are from poor families, especially at less selective colleges. Pew Research Center: $1-16$

Gholipour S, Nikaeen M, Manesh RM, Aboutalebian S, Shamsizadeh Z, Nasri E, Mirhendi H (2020) Severe acute respiratory syndrome coronavirus 2 (SARS-CoV-2) contamination of high-touch surfaces in field settings. Biomed Environ Sci 33:925-929

Gholipour S, Mohammadi F, Nikaeen M, Shamsizadeh Z, Khazeni A, Sahbaei Z, Mousavi SM, Ghobadian M, Mirhendi H (2021) COVID-19 infection risk from exposure to aerosols of wastewater treatment plants. Chemosphere 273:129701

Gyimah NJAaS (2020) Assessing technological innovation on education in the world of coronavirus (COVID-19). https://doi.org/10.2139/ ssrn.3670389

Hasan N, Bao YJC, Review YS (2020) Impact of "e-Learning crack-up" perception on psychological distress among college students during COVID-19 pandemic: a mediating role of "fear of academic year loss". Child Youth Serv Rev 118:105355

Hoq MZJAJER (2020) E-learning during the period of pandemic (COVID-19) in the kingdom of Saudi Arabia: an empirical study. Am J Educ Res 8:457-464

Hussein NR, M Saleem ZS, Musa DH, et al. (2020) Impact of COVID-19 on the medical education: experience from Kurdistan region of Iraq. J Med Educ 19(1):e106889

Iqbal S, Zang X, Zhu Y, et al (2015) Towards moocs and their role in engineering education. 2015 7th International Conference on Information Technology in Medicine and Education (ITME). IEEE, 705-709

Jiang SJC, Review YS (2020) Psychological well-being and distress in adolescents: an investigation into associations with poverty, peer victimization, and self-esteem. Child Youth Serv Rev 111:104824

Kalantary RR, Jamshidi A, Mofrad MMG, Jafari AJ, Heidari N, Fallahizadeh S, Arani MH, Torkashvand J (2021) Effect of COVID-19 pandemic on medical waste management: a case study. J Environ Health Sci Eng. https://doi.org/10.1007/s40201-02100650-9

Kapasia N, Paul P, Roy A, Saha J, Zaveri A, Mallick R, Barman B, Das P, Chouhan P (2020) Impact of lockdown on learning status of undergraduate and postgraduate students during COVID-19 pandemic in West Bengal, India. Child Youth Serv Rev 116:105194

Lambert KJPE, Pedagogy S (2020) Re-conceptualizing embodied pedagogies in physical education by creating pre-text vignettes to trigger pleasure 'in'movement. Phys Educ Sport Pedagog 25:154-173

Lawal B, Haruna A, Kurfi F et al (2020) COVID-19 pandemic and pharmacy education in a developing country: a case study from Nigeria. Pharm Educ 20:15-16
Leszczyński P, Charuta A, Łaziuk B, Gałązkowski R, Wejnarski A, Roszak M, Kołodziejczak B (2018) Multimedia and interactivity in distance learning of resuscitation guidelines: a randomised controlled trial. Interact Learn Environ 26:151-162

Mishra L, Gupta T, Shree AJIJERO (2020) Online teaching-learning in higher education during lockdown period of COVID-19 pandemic. Int J Educ Res Open 1:100012

Nguyen JG, Keuseman KJ, Humston JJJJCE (2020) Minimize online cheating for online assessments during COVID-19 pandemic. J Chem Educ 97:3429-3435

Sangster A, Stoner G, Flood BJAE (2020) Insights into accounting education in a COVID-19 world. Acc Educ 29:431-562

Settersten RA Jr, Bernardi L, Härkönen J, Antonucci TC, Dykstra PA, Heckhausen J, Kuh D, Mayer KU, Moen P, Mortimer JT, Mulder CH, Smeeding TM, van der Lippe T, Hagestad GO, Kohli M, Levy R, Schoon I, Thomson E (2020) Understanding the effects of Covid19 through a life course lens. Adv Life Course Res 45:100360

Shea L-MJP, Sciences tH (2020) No perfect syllabus for distance learning: DBT skills for deciding how to teach throughout uncertainty. Pedagog Hum Sci 7:10

Subedi S, Nayaju S, Subedi S et al (2020) Impact of E-learning during COVID-19 pandemic among nursing students and teachers of Nepal. Int J Sci Healthc Res 5:68-76

Torkashvand J, Jafari AJ, Godini K, Kazemi Z, Kazemi Z, Farzadkia M (2021) Municipal solid waste management during COVID-19 pandemic: a comparison between the current activities and guidelines. $\mathrm{J}$ Environ Health Sci Eng:1-7. https://doi.org/10.1007/s40201-02000591-9

Wadhwa N, Khatak SJJSS (2020) Online versus offline mode of education-is India ready to meet the challenges of online education in lockdown? J Soc Sci 48(3):404-413

Wang G, Zhang Y, Zhao J, Zhang J, Jiang F (2020) Mitigate the effects of home confinement on children during the COVID-19 outbreak. Lancet 395:945-947

Wong YC, Ho KM, Chen H, Gu D, Zeng Q (2015) Digital divide challenges of children in low-income families: the case of Shanghai. J Technol Hum Serv 33:53-71

Yousefi M, Oskoei V, Jafari AJ, Farzadkia M, Firooz MH, Abdollahinejad B, Torkashvand J (2021) Municipal solid waste management during COVID-19 pandemic: effects and repercussions. Environ Sci Pollut Res. https://doi.org/10.1007/s11356-02114214-9

Publisher's note Springer Nature remains neutral with regard to jurisdictional claims in published maps and institutional affiliations. 